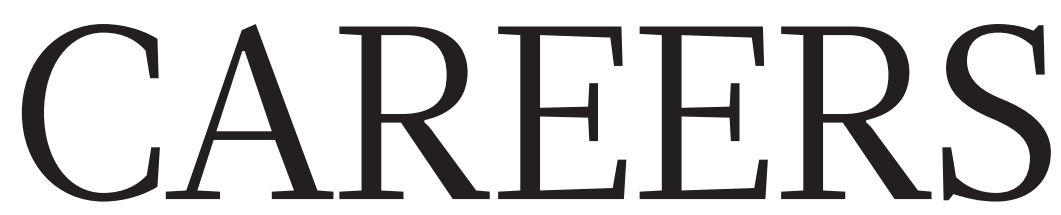

IMMIGRATION Ireland eases path for postgraduates $\mathbf{p} .141$

EQUITY Diversity takes a step ahead in Canada p.141

NATUREJOBS For the latest career listings and advice www.naturejobs.com

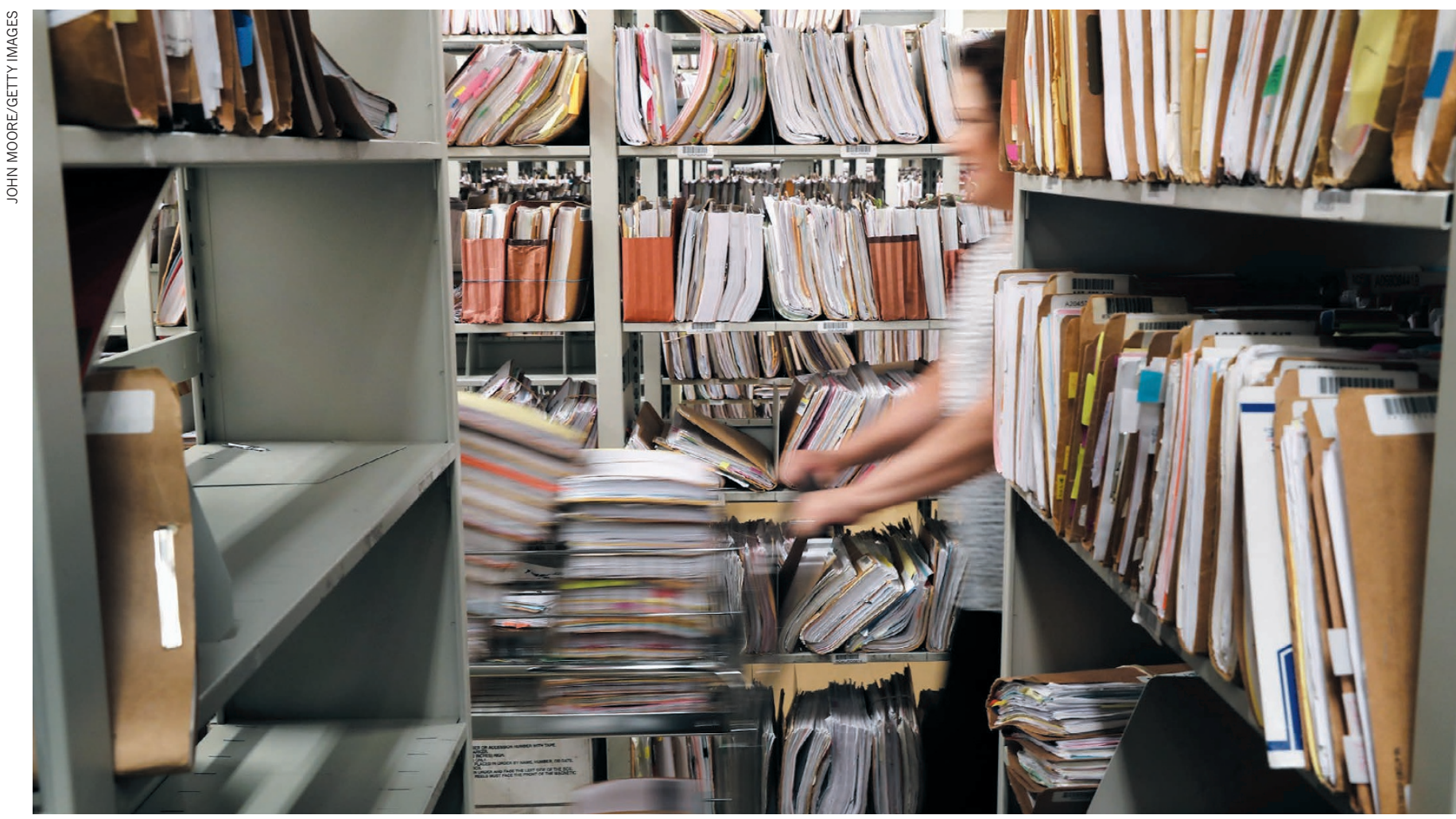

US Citizenship and Immigration Services officers handle millions of green-card applications each year from immigrants seeking permanent residency.

\title{
Access denied
}

\section{Political change is causing scientists worldwide to worry about how immigration law might affect their ability to do research.}

\section{BY CHRIS WOOLSTON}

A s a neurologist, Sangeet Lal should be exhausting his mental energy on neurons and meninges. But Lal, who is from India, has spent much of the past ten years battling for the visas that he needs to continue studying and working in the United States. "It has slowed me down and hurt my career," says Lal, a postdoc at the University of California, San Francisco. "Foreign students have to struggle through the system. A lot of people are suffering."

Science is an international enterprise. As of 2013,27\% of scientists and engineers in the United States were born in a foreign country, according to a 2016 report from the US National Science Foundation (see go.nature. com/2md8lro). And the Campaign for Science and Engineering, an organization based in London, reported last year that some $13 \%$ of university faculty members in scientific fields in the United Kingdom came from outside the European Union, and another 17\% from other EU countries (see go.nature.com $/ 2 \mathrm{mljwzc}$ ).

But in both the United States and the United Kingdom - two science hubs undergoing

\begin{tabular}{|l|l|}
\hline & HUMAN MIGRATION \\
& $\begin{array}{l}\text { A Nature special issue } \\
\text { nature.com/migration }\end{array}$ \\
\hline
\end{tabular}

political upheaval - foreign researchers and those recruiting them must navigate a bureaucratic maze that threatens to become even more complicated. The election of Donald Trump as US president and the UK vote to leave the EU, known as Brexit, have added fear and uncertainty to the immigration picture on both sides of the Atlantic Ocean. "Everyone is having a nervous breakdown," says Azra Raza, an oncologist who frequently hires foreign researchers for her lab at Columbia University in New York City. "No one knows what's coming."

The immigration system in both nations already hampers science, say many researchers. Anne Glover, a microbiologist at the University of Aberdeen, UK, and former 
chief scientific adviser to the president of the European Commission (EC), says that in the past few years, she has had trouble bringing postdocs and graduate students from Asia and North America to her lab. "The UK seems to be starting with the premise that we don't want to let anyone in," she says. "We all depend on good collaboration that requires freedom of movement. We're giving ourselves an unnecessary handicap."

Lee Cronin, a chemist at the University of Glasgow, UK, aired his frustrations with immigration policy on Twitter last May: "I'm embarrassed to be a UK scientist right now. It's taken $>6$ months to get visas for two amazing researchers essential to UK science," he wrote.

\section{BURDENS OF PROOF}

In the fast-paced world of science, Cronin says, such delays can be crippling to research, especially in small labs that do not have many other people to pick up the slack. In his case, delays have often centred on a requirement that workers from non-English-speaking countries prove proficiency in English to get a tier-2 UK work visa, a type of permit set aside for highly skilled workers. This might seem to be an easy hurdle to clear - most applicants, after all, wrote their dissertations in English and spoke English during job interviews. But the test required of many applicants is offered only at certain times at certain sites, and so the vetting process can take months.

Long waits for English-proficiency tests have also vexed Stefan Bon, a chemical engineer at the University of Warwick in Coventry, UK. Last year, one of his postdocs had to travel from Germany to the Netherlands to take the test, and the whole process - scheduling it, taking it and waiting for the results - took almost six months. Bon says that principal investigators (PIs) should expect delays, and that all prospective lab members should take the test as early as possible.

UK PIs have had to become de facto experts in immigration policy to keep their labs staffed. To get a UK work visa, scientists from nonEU nations must make the case that they have unique skills to contribute. Cronin says that he turns this legal requirement to his advantage by making job announcements as specific as possible. If a researcher meets all of the requirements, it's easier to show immigration authorities that they deserve a visa. He also advertises as early as possible to give prospective employees more time to get a visa if needed.

A UK government spokesperson says that the government recognizes the crucial contributions of science to the UK economy and society. "We welcome the brightest students and academics coming to our world-leading educational institutions," the spokesperson says, adding that, although the United Kingdom has restricted the number of visas granted to workers from other professions since 2010, highly skilled workers such as scientists still enjoy a "higher priority".

Raza also has to advocate for overseas researchers whom she is recruiting. "You have to establish that they are going to bring something special," she says. "You should document everything you can before applying. Even then, you should expect long delays." Raza, who herself is from Pakistan and is now a US citizen, says that she has successfully recruited more than 100 foreign members to her lab in the past 25-odd years, but that, in her experience, the system was getting more difficult and restrictive even before the latest presidential election.

Virginia Elliott, a spokesperson for the US Bureau of Consular Affairs, says that "all visas are adjudicated on a case-by-case basis

\section{LEGALLY FIT}

\section{Tactics for an airtight visa case}

Scientists hoping to emigrate to the United States or the United Kingdom to study or work often underestimate the challenge and complexity of the visa process, says Dom Schunker, a senior partner at Skillclear, an immigration consultation firm in Sevenoaks, UK. His advice: "Don't apply for anything until you've asked for help." Here are some tips: - Talk to someone who can explain your options. You don't necessarily need a lawyer or an immigration firm, he says, but the person should be able to guide you through the basics, such as which visa to apply for. Schunker warns that both UK and US officials are increasingly looking for reasons to deny applications, and so even highly qualified scientists might end up in the reject pile.
- Get your educational record formally translated and validated. Without that stamp of approval, all your achievements could be discounted. Validation services are provided, in the United Kingdom, by NARIC, based in Cheltenham, and, in the United States, by organizations such as World Education Services, based in New York City. - Make sure your financial affairs are in order. "If you owe a bill to someone, pay it," Schunker says. "Any record of non-payment will get you stopped at the border." - Get started now. Researchers who aim to study or work in the United States or United Kingdom cannot delay. Investigate the requirements and consider options immediately: the process is likely to take a long time. C.W.

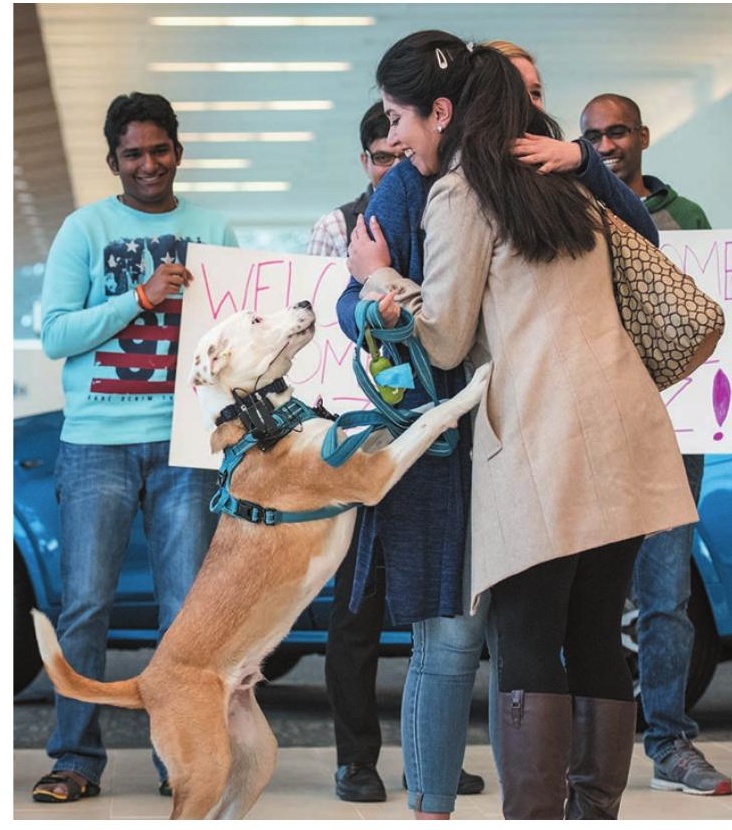

An Iranian engineer returns to the United States.

in accordance with immigration law regardless of profession." She declined to comment specifically on the immigration requirements for foreign researchers.

For scientists working overseas, immigration problems can shatter their personal lives as well. Even after a decade of work in the United States, Lal still feels as if he's on uncertain ground. In early January, he and his wife had to travel back to India for a family emergency, and he wasn't sure how long he would have to wait for approval for re-entry - a requirement for those with his type of visa - into the United States, or whether he could even return at all. "If I can get a visa, I'll come back," he says. "If they don't approve it, I'll lose my job and all of my possessions." (Lal was indeed granted re-entry, just before this issue of Nature went to press.)

Like many foreign postdocs, Lal works in the United States on an H-1B non-immigrant visa, a permit set aside for people in speciality occupations, such as scientists, engineers and physicians. To qualify, a visiting scientist must have a sponsoring employer who pledges to keep her or him employed. The visa system gives PIs extra power over their foreign lab members, $\mathrm{Lal}$ says: because visa holders need a sponsor to stay in the country, PIs and other employers could theoretically overwork and underpay foreign workers without much fear that they'll quit (see page 29). Federal law requires sponsors to pay $\mathrm{H}$-1B-visa holders a wage at least equal to that of non-immigrant workers with similar qualifications, but salaries and work hours are still largely at the PI's discretion. "Some employers are really bad," Lal says, recalling the experiences of several friends and colleagues. "They know how to exploit workers in the visa system."

If things aren't working out in the lab, visiting scientists need to find another sponsor, a process that has to be approved by US Citizenship 
and Immigration Services. If they can't find one, they must leave the country or change their immigration status. Lal says that his wife had to give up her $\mathrm{H}-1 \mathrm{~B}$ for an $\mathrm{H}-4$ dependent visa - conditionally available to immediate family members of someone on an $\mathrm{H}-1 \mathrm{~B}$ visa - after losing her research position. H-4-visa holders generally aren't allowed to work, so Lal has to support the family himself.

\section{APPLICATION LABRYINTH}

Foreign researchers who want to work in the United States should be upfront about immigration issues when interviewing for positions, Lal says. "Many PIs have no idea about visa requirements," he says. "I was very clear with potential employers. I told them that I needed them to sponsor my visa. Having that nailed down before you join a lab protects you from exploitation." He says that he also checked with other international lab members to see if they'd had any trouble. "It takes courage to bring up this topic during an interview," he says. "But you have to be clear about your goals. Visa issues can give people nightmares," he adds (see 'Tactics for an airtight visa case').

Scientists can gain a more secure footing by applying for a 'green card', a type of visa that confers permanent-residency status. Green cards have already been a source of contention in the White House. Days after Trump issued a 90-day travel restric-

tion on entry into the United States for nationals of seven countries, his chief of staff announced that green-card holders from those "No country
has enough
talent to do
quality science.
Youneed
immigrants." countries would be admitted on a case-by-case basis. The ban was halted in mid-February, but a new executive order was expected to be released the following week.

Anyone seeking a green card should start the process a couple of years in advance, says Neilia Gracias, a neuroscientist at the University of California, Davis, who received her green card in 2014. Gracias, who is from India, says that her application was nearly 1,000 pages long, a testament to the complexity of the endeavour. The application included a 25-page personal statement that took her a month to write. She also had ten letters of recommendation - and importantly, sought out scientists who were familiar with her work but didn't know her personally. "They are assessing skills," she says. "It doesn't matter if you're a diligent worker or can get along with people."

Scientists who want a green card must demonstrate a track record of publishing papers and winning grants. But with citizenship on the line, the pressure to succeed is especially intense, Gracias says. "You need to start building credentials," she says. "If you aren't getting publications, you might have to change labs."
As do many in her position, Gracias decided to hire a lawyer to help with the process. "There was no way I was going to do it on my own," she says. Lawyers can charge as much as US\$5,000 for the service, but Gracias got a discount from a qualified friend. Among other things, the lawyer helped her to make the case that she had valuable skills to offer her new country. The lawyer also included a picture of a neuron on the application, an eyecatching touch to underscore the importance of her research. Gracias waited a year for her green card to be approved - longer than some people she knows, but shorter than others. "I don't think it should be so hard for highly educated people to get a green card," she says. "No country has enough talent to do quality science. You need immigrants."

Raza says that the travel restrictions announced by the Trump administration confirmed some of her worst fears. "The holder of the highest office in the world is calling out and saying 'stay away," she says. The uncertainty surrounding the nation is already making it harder to recruit foreign researchers, she adds. "Some people don't want to come to the United States. If they can get a position in Europe or Asia, why would they want to come here?"

Similarly, Glover worries that the Brexit vote might make it harder to recruit foreign talent. On a practical level, Brexit might mean that researchers who come to the United Kingdom may no longer be able to apply for EU grants or participate in EU consortia. "If I was an American scientist, I might decide to go to Germany or Spain instead," she says. And then there's the symbolism. The vote has sent a message to researchers worldwide that the United Kingdom might not be a welcoming place, Glover says. "Whether that's reality or not, that's the perception."

Cronin says that he'll be keeping close tabs on any shift in immigration policies under UK Prime Minister Theresa May. "If things change direction, I'll start lobbying," he says. "If it becomes impossible for me to get the right people, I would leave the UK and move the lab to a more open-minded country where excellence is the only requirement." He adds that he's still hopeful that the United Kingdom will continue to be a beacon for top-notch scientists from around the world. "But," he says, "I have my doubts."

\section{Chris Woolston is a freelance writer in} Billings, Montana.

\section{CORRECTION}

The Careers Feature 'Cultivate the muse' (Nature 542, 381-383; 2017) incorrectly described Gaia Bistulfi as a computational biologist. She is, in fact, a molecular biologist.

\section{POSTGRADUATES}

\section{Ireland beckons}

Postgraduates from outside the European Union who have earned doctoral or master's degrees at institutions in Ireland now have up to 24 months to seek employment in the country after graduating. The Irish government doubled the 'stay-back' period from the earlier one-year cut-off. During the two-year period, holders of $\mathrm{PhDs}$ or master's degrees can seek a green-card visa or work permit, look for a job and work for up to 40 hours a week. Ministers announced the policy on 2 February, six days after US President Donald Trump tried to block entry into the United States for citizens of seven Muslimmajority nations. Last October, the Irish government unveiled its 'Irish Educated, Globally Connected' strategy, which aims to increase Ireland's international-student enrolment from 33,118 in 2014/2015 to 44,000 by the end of $2019 / 2020$ and revenue from those students from $€ 1.58$ billion (US $\$ 1.67$ billion) annually to $€ 2.1$ billion. Under the strategy, Ireland is also targeting students from Canada, Mexico, Chile, Argentina, South Korea, Vietnam, Indonesia and Nigeria.

\section{EQUITY}

\section{One step forward}

One in five faculty members at York University in Toronto, Canada, could come from minority communities following an agreement between the institution's faculty association and the university, according to a report by the Canadian Association of University Teachers (CAUT). The university also agreed to recruit at least four Aboriginal academics and acknowledged that staff members who are from lesbian, gay, bisexual, transgender, queer and two-spirit (LGBTQ2S) communities are an 'underrepresented group. The agreement comes after a decade of negotiations between Canadian faculty unions and universities on an equity agenda. Several unions have made gains for women, Aboriginal peoples, the LGBTQ2S community and those with disabilities. In its report, CAUT - which represents 30,000 faculty researchers and other education professionals - said that a government minister has agreed to tackle equity in federal research programmes. Last autumn, CAUT reiterated to the government that fundamental research programmes must be inclusive and reflect the diversity of Canada's research community. 